\title{
Diabetes as a risk factor for heart failure in women and men: a systematic review and meta-analysis of 47 cohorts including 12 million individuals
}

\author{
Toshiaki Ohkuma $^{1}$ (D) Yuji Komorita ${ }^{2,3} \cdot$ Sanne A. E. Peters ${ }^{4} \cdot$ Mark Woodward $^{1,4,5}$
}

Received: 25 February 2019 / Accepted: 10 May 2019 /Published online: 18 July 2019

(C) The Author(s) 2019

\begin{abstract}
Aims/hypothesis The prevalence of diabetes and heart failure is increasing, and diabetes has been associated with an increased risk of heart failure. However, whether diabetes confers the same excess risk of heart failure in women and men is unknown. The aim of this study was to conduct a comprehensive systematic review with meta-analysis of possible sex differences in the excess risk of heart failure consequent to diabetes. Our null hypothesis was that there is no such sex difference.

Methods A systematic search was conducted in PubMed for population-based cohort studies published between January 1966 and November 2018. Studies were selected if they reported sex-specific estimates of RRs for heart failure associated with diabetes, and its associated variability, which were adjusted at least for age. Random-effects meta-analyses with inverse variance weighting were used to obtain pooled sex-specific RRs and women-to-men ratio of RRs (RRRs) for heart failure associated with diabetes.

Results Data from 47 cohorts, involving 12,142,998 individuals and 253,260 heart failure events, were included. The pooled multiple-adjusted RR for heart failure associated with type 1 diabetes was 5.15 (95\% CI 3.43, 7.74) in women and $3.47(2.57,4.69)$ in men, leading to an RRR of $1.47(1.44,1.90)$. Corresponding pooled RRs for heart failure associated with type 2 diabetes were $1.95(1.70,2.22)$ in women and $1.74(1.55,1.95)$ in men, with a pooled RRR of 1.09 (1.05, 1.13).

Conclusions/interpretation The excess risk of heart failure associated with diabetes is significantly greater in women with diabetes than in men with diabetes.
\end{abstract}

PROSPERO registration: CRD42019135246

Keywords Diabetes $\cdot$ Heart failure $\cdot$ Meta-analysis $\cdot$ Sex differences $\cdot$ Systematic review

Electronic supplementary material The online version of this article (https://doi.org/10.1007/s00125-019-4926-x) contains peer-reviewed but unedited supplementary material, which is available to authorised users.

Toshiaki Ohkuma

tohkuma@georgeinstitute.org.au

Sanne A. E. Peters

speters@georgeinstitute.org.uk

1 The George Institute for Global Health, University of New South Wales, Level 10, King George V Building, Royal Prince Alfred Hospital, Missenden Road, Camperdown, Sydney, NSW 2050, Australia
2 Department of Medicine and Clinical Science, Graduate School of Medical Sciences, Kyushu University, Fukuoka, Japan

3 Division of Internal Medicine, Fukuoka Dental College, Fukuoka, Japan

4 The George Institute for Global Health, University of Oxford, Hayes House, 75 George Street, Oxford OX1 2BQ, UK

5 Department of Epidemiology, Johns Hopkins University, Baltimore, MD, USA 


\section{Research in context}

\section{What is already known about this subject?}

- Diabetes is associated with an increased risk of heart failure

- Accumulating evidence has found that, compared with men, women have a significantly greater excess risk of cardiovascular diseases, such as CHD and stroke, following diagnosis of diabetes

- Whether diabetes confers the same excess risk of heart failure in women and men is unknown

\section{What is the key question?}

- Does diabetes confer a greater excess risk of heart failure in women than men?

\section{What are the new findings?}

- The present meta-analysis of 47 cohorts, including more than 12 million individuals, showed that both type 1 and type 2 diabetes were stronger risk factors for heart failure in women than men

- Type 1 diabetes was associated with a $47 \%$ greater excess risk of heart failure in women compared with men

- Type 2 diabetes was associated with a 9\% greater excess risk of heart failure in women than men

How might this impact on clinical practice in the foreseeable future?

- This study sheds light on the importance of a routine sex-specific approach in both diabetes research and clinical practice

\section{Abbreviation \\ RRR Ratio of RR}

\section{Introduction}

Diabetes and heart failure are now recognised as frequent comorbid conditions; the prevalence of type 2 diabetes in individuals with heart failure was reported to be $4.3-28 \%$, whilst that of heart failure in those with type 2 diabetes was reported to be $12-57 \%$ [1]. Diabetes is associated with an increased risk of heart failure [2], and also increases the risk of premature death after diagnosis of heart failure [3, 4]. Furthermore, heart failure is the second most common initial presentation of cardiovascular disease in people with type 2 diabetes and more common than myocardial infarction or stroke [5]. Although heart failure appears to be a complication of diabetes [6], this is still not fully recognised [1]. The number of people with heart failure is expected to increase continuously in the future, and thus efficient earlier prevention and treatment of heart failure is crucial.

Accumulating evidence has found that there are considerable sex differences in the excess risk of cardiovascular diseases associated with diabetes [7]. Our previous metaanalyses have shown that, compared with men, women have a significantly greater excess risk of CHD [8], stroke [9], as well as the non-cardiovascular complications of dementia [10], and cancer [11], following diabetes. However, whether these associations are also observed for heart failure is unknown, as the previous meta-analysis on the diabetesheart failure association [2] included single-sex studies, which may have led to unreliable results due to differences in methodology, confounding factors included and background risk between the studies of women alone and men alone. Herein, we report the most comprehensive systematic review of the literature with a meta-analysis of possible sex differences in the excess risk of heart failure consequent to diabetes using only studies that included both sexes.

\section{Methods}

Search strategy and selection criteria We conducted a systematic search in PubMed on 16 November 2018 using a combination of text words and medical subject headings (electronic supplementary material [ESM] Table 1). The reference lists of identified studies were also reviewed to identify other relevant studies.

Observational cohort studies were included if they had provided sex-specific RRs, or equivalents, for the association between diabetes and heart failure in both women and men. Studies were excluded if they were cohorts based on individuals with any underlying diseases, reported data for a single sex only, did not adjust at least for age, or did not provide information about the variability around the point estimate. In cases of duplicate reports from the same study, the study providing the longest follow-up or the highest number of events was included. Two authors (T. Ohkuma and Y. 
Komorita) conducted the search and extracted the data independently, and uncertainties regarding the inclusion of studies and data extraction were discussed and resolved by mutual consent. The meta-analysis was conducted in accordance with Meta-analysis Of Observational Studies in Epidemiology (MOOSE) guidelines [12].

Data extraction and statistical analysis The primary outcome was incident heart failure (either fatal or non-fatal). The primary metrics were the pooled multiple-adjusted sex-specific RRs and the women-to-men ratio of RRs (RRRs) for heart failure, comparing individuals with diabetes with those without diabetes. In pooling multiple-adjusted RRs, the set of adjustments made was allowed to vary by study, but had to include at least one other risk factor for heart failure, in addition to age. Multiple RRs of subgroups from one study were combined into a single RR using a fixed-effect model. The pooled estimates of sex-specific RRs across studies were computed using random-effects meta-analyses with inverse variance weighting applied on the log scale. The same method was used to pool the RRRs. Data on type 1 and type 2 were separately pooled, where studies which did not differentiate type of diabetes were classified as type 2, which accounts for about $90-95 \%$ of all individuals with diabetes [13]. The $I^{2}$ statistic was used to estimate the percentage of variability across studies due to between-study heterogeneity. Cochran's $Q$ test was used to assess whether there was a significant between-study heterogeneity.
Age-adjusted RRs were also pooled separately in secondary analyses. A sensitivity analysis was conducted to compare multiple-adjusted and age-adjusted estimates, where the studies were restricted to those that reported both. The presence of publication bias was examined using funnel plots and Egger's and Begg's tests. Meta-regression analyses tested for differences between prespecified subgroups in multiple-adjusted analyses: study region (Asia or non-Asia), year of baseline study (pre-1985 or 1986 onwards), ascertainment of diabetes (self-reported only or others), study outcome (fatal only or fatal and non-fatal combined), study quality (the NewcastleOttawa Scale [14] [ESM text and ESM Table 2], $\geq 8$ or $<8$ points) and by absolute risk differences (greater in men or greater in women). Since only two studies were identified for type 1 diabetes, the analyses described in this paragraph were only applied for type 2 diabetes.

A $p$ value $<0.05$ was considered to be statistically significant. All analyses were performed using Stata software (release 13; StataCorp, College Station, TX, USA).

\section{Results}

Of the 5991 articles identified by the systematic search, 760 articles qualified for full-text evaluation, and 14 articles provided summary data for sex differences in the association between diabetes and the risk of heart failure [5, 15-27] (Fig. 1).
Fig. 1 Flow chart of study selection

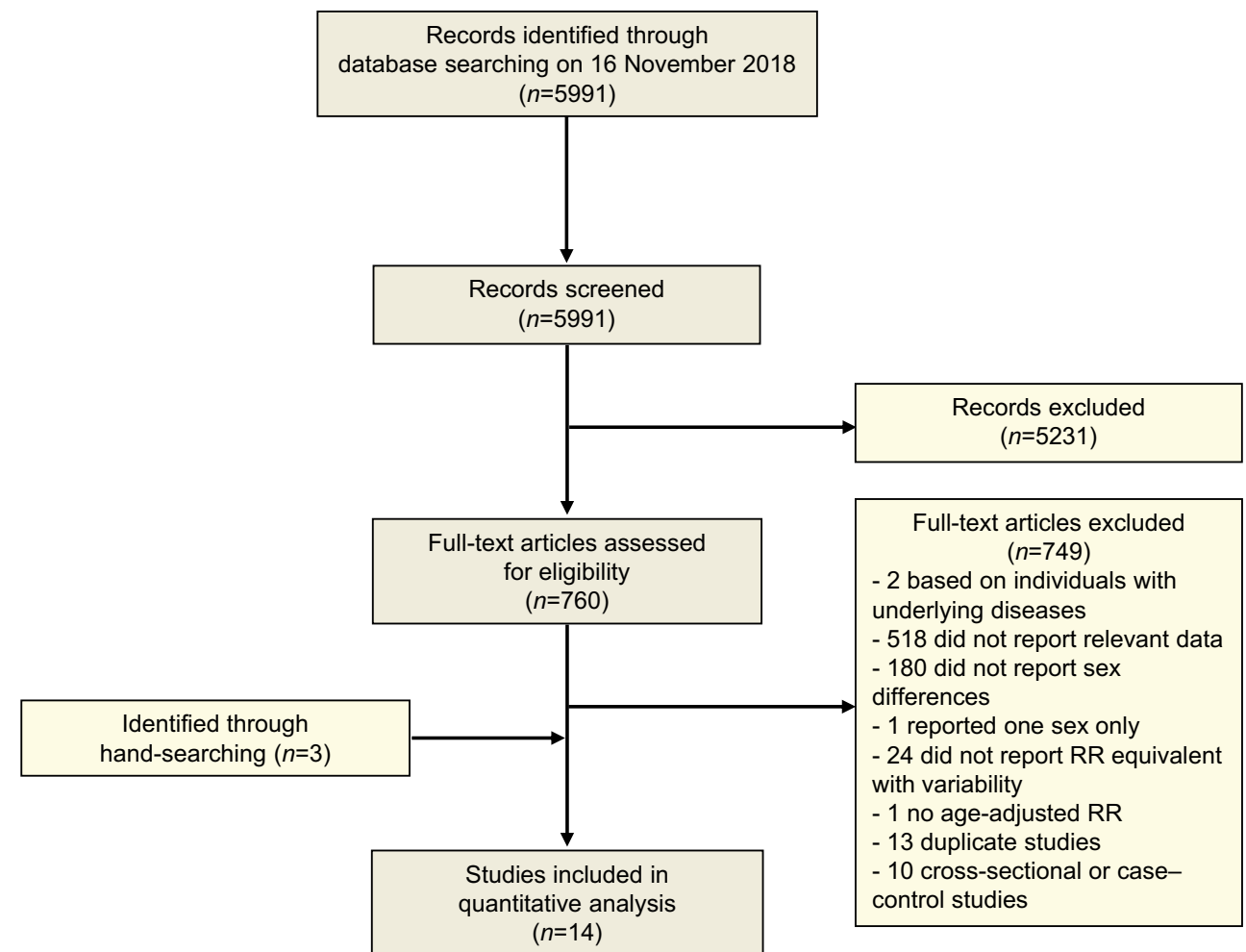




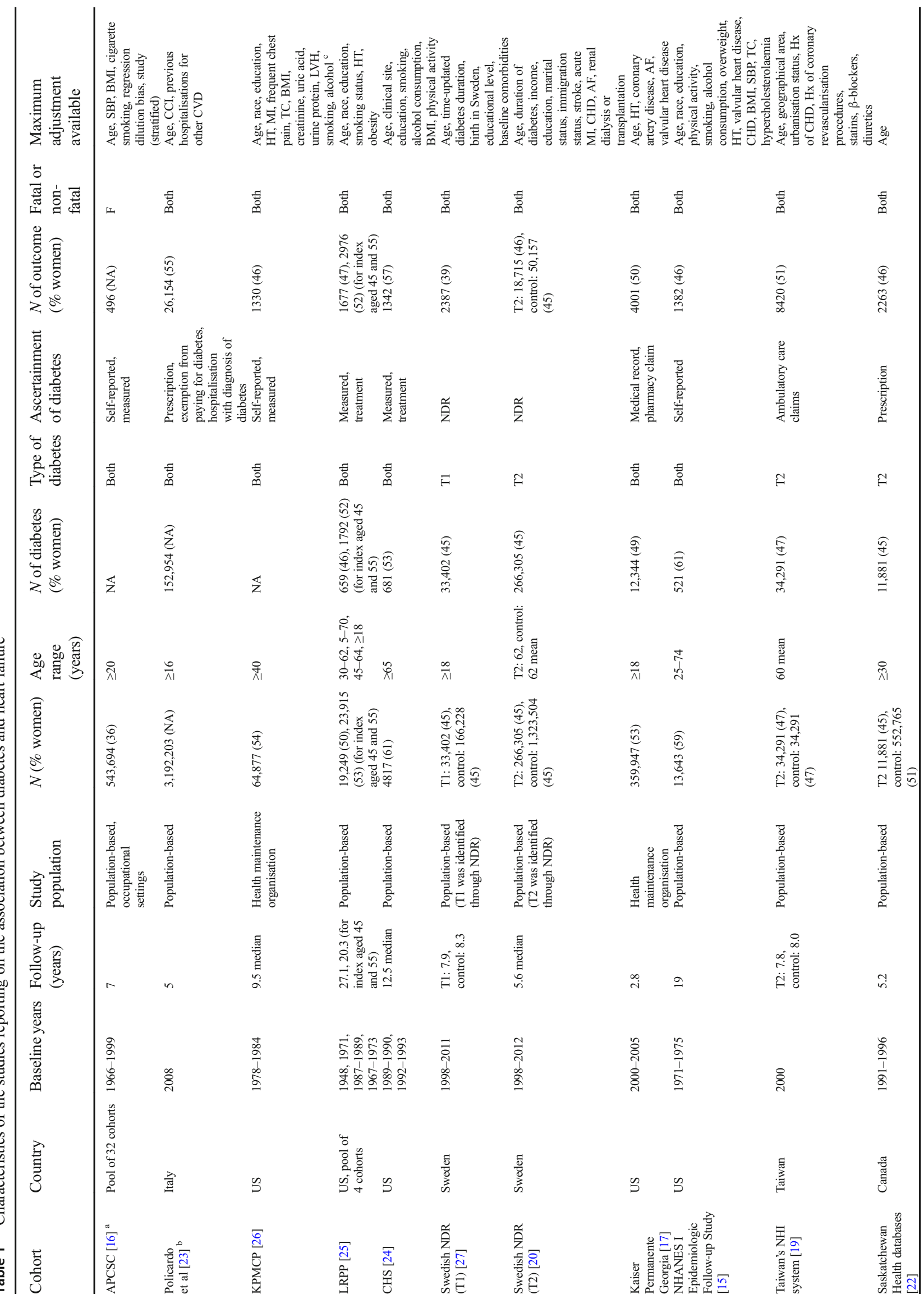




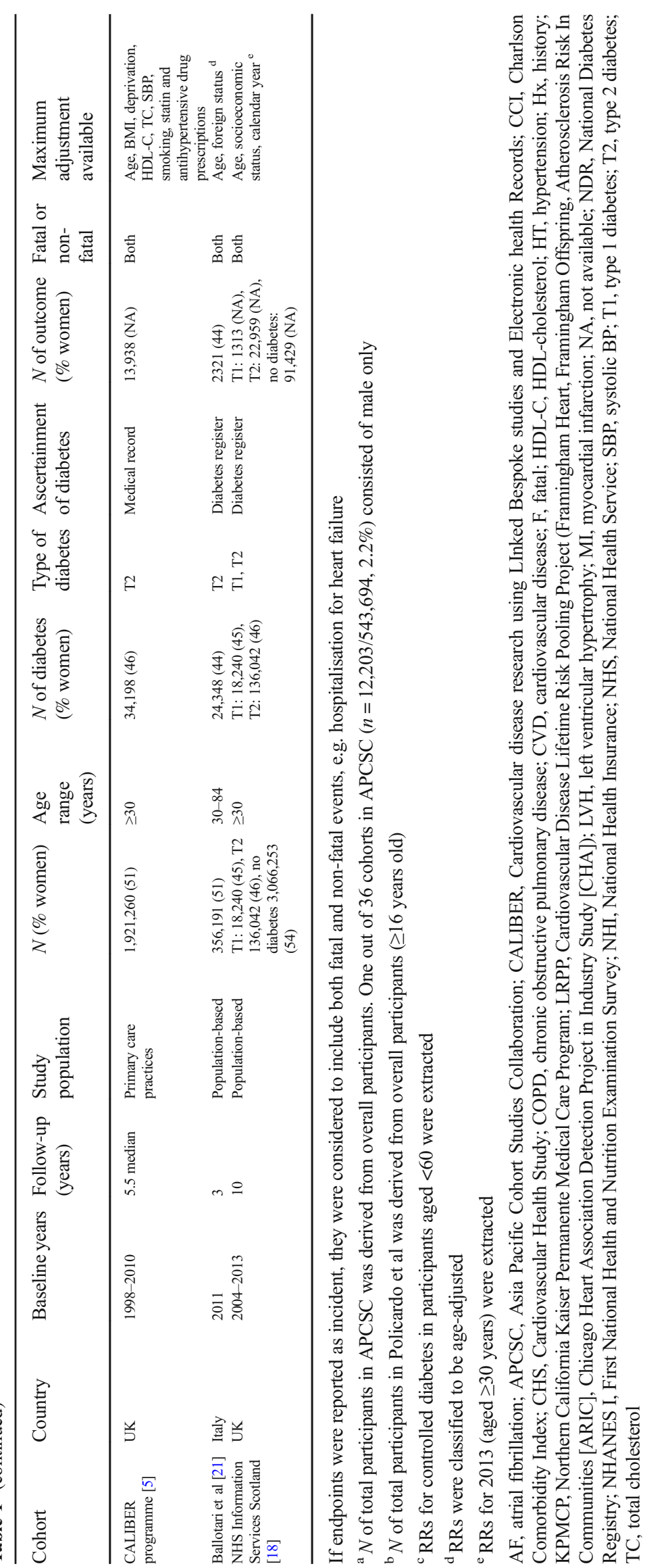


The characteristics of all 14 studies included are shown in Table 1 and ESM Table 2. Data on type 1 diabetes and heart failure were available from two studies, involving two cohorts, including 3,284,123 individuals, and 95,129 events. Data on type 2 diabetes and heart failure were available from 13 studies, involving 47 cohorts, including 11,925,128 individuals, and 249,560 events, among which two studies, involving two cohorts, including 368,072 individuals, and 4584 events, reported age-adjusted RRs only. Nine studies provided data on absolute risks (ESM Table 3).

The multiple-adjusted pooled sex-specific RRs for heart failure associated with type 1 diabetes were 5.15 (95\% CI $3.43,7.74, p<0.001)$ in women and $3.47(2.57,4.69$, $p<0.001$ ) in men (Fig. 2). The pooled multiple-adjusted RRR indicated a significantly greater excess risk for heart failure in women with type 1 diabetes compared with men. The women-to-men RRR was 1.47 (1.14, 1.90, $p=0.003$ [Fig. 3]). The $I^{2}$ statistics for heterogeneity between studies were $0.0 \%$.

The sex-specific RRs for heart failure associated with type 2 diabetes was 1.95 (95\% CI 1.70, 2.22, $p<0.001)$ in women and $1.74(1.55,1.95, p<0.001)$ in men (Fig. 2), with the women-to-men RRR of $1.09(1.05,1.13), p<0.001, I^{2}=$ $0.0 \%$ (Fig. 3). There was no evidence of publication bias for the association between type 2 diabetes and heart failure (Egger's test $p=0.27$, Begg's test $p=0.31$, ESM Fig. 1). In subgroup analyses, the pooled women-to-men multipleadjusted RRR did not differ significantly by study region $(p=0.29)$, year of baseline study $(p=0.87)$, ascertainment of diabetes $(p=0.72)$, study outcome ( $p=0.41)$, quality of study $(p=0.25)$, or absolute risk differences between men and women $(p=0.16)$ (Fig. 4).

For type 2 diabetes, five studies provided age-adjusted estimates. The pooled age-adjusted sex-specific RRs for heart failure associated with diabetes were 2.56 (95\% CI 2.31, 2.84, $p<0.001)$ in women and $2.49(2.04,3.04, p<0.001)$ in men. The pooled age-adjusted women-to-men RRR for heart failure was $1.00(0.78,1.27, p=0.98)$. The $I^{2}$ statistics for heterogeneity between studies was $87.6 \%$, suggesting substantial heterogeneity.

In sensitivity analysis, restricted to studies which provided the sex-specific RRs for both multiple-adjusted and ageadjusted models, the pooled women-to-men RRR was 1.17 (95\% CI 1.02, 1.35, $p=0.02$ ) for multiple-adjusted analysis, and $1.19(1.06,1.34, p=0.005)$ for age-adjusted analysis (ESM Fig. 2).

\section{Discussion}

The present meta-analysis, of 47 cohorts including more than 12 million individuals, showed that both type 1 and type 2 diabetes were a stronger risk factor for heart failure in women than men. Type 1 diabetes was associated with a $47 \%$ greater excess risk of heart failure in women compared with men, and type 2 diabetes was associated with a $9 \%$ greater excess risk of heart failure in women than men. The sex difference in the association between type 2 diabetes and heart failure was consistent across a range of prespecified subgroups. These findings are in agreement with the previous evidence showing that diabetes has stronger associations with diabetic complications for women than men, and shed light on the importance of a routine sex-specific approach both in research and clinical practice in this field.

A previous meta-analysis reported that diabetes was associated with the risk of heart failure in both women and men [2]. However, this previous meta-analysis included studies consisting of women or men only, as well as studies among both women and men, and therefore could have introduced bias in quantifying sex differences. Further, sex-specific RRs were not reported for type 1 diabetes. The present metaanalysis includes additional two-sex studies that were not included previously, and provides evidence that both type 2 diabetes and type 1 diabetes are a risk factor for heart failure in both sexes, with significantly stronger associations in women than men. These findings suggest that healthcare providers and policy makers should be aware of this greater excess risk of heart failure, as well as other diabetic complications [8-11, $28,29]$, in women than men.

In our analyses of type 2 diabetes, the women-to-men RRR was greater when multiple-adjusted RRs were pooled compared with when age-adjusted RRs were pooled (multiple-adjusted RRR 1.09 [95\% CI 1.05, 1.13] vs age-adjusted RRR $1.00[0.78,1.27])$. A significant degree of heterogeneity between studies was observed for age-adjusted analyses $\left(I^{2}=\right.$ $87.6 \%, p<0.001)$, but not for multiple-adjusted analyses $\left(I^{2}=0.0 \%, p=0.834\right)$. On the other hand, the sensitivity analysis including the studies that reported both multiple-adjusted and age-adjusted estimates provided almost similar results, indicating a greater excess risk of heart failure associated with diabetes in women than men. Therefore, we speculate that the difference observed between multiple-adjusted and ageadjusted analyses is likely due to chance differences between the studies included. Furthermore, we believe that multipleadjusted estimates, which adjust for other major cardiovascular risk factors in addition to age, are more likely to represent true aetiology.

There are several potential explanations for the greater excess risk of heart failure associated with diabetes in women compared with men. First, the observed sex differences could be driven by there being a greater risk of CHD conferred by diabetes in women than men, because CHD is a major cause of heart failure in people with type 2 diabetes [1]. Our previous large-scale meta-analyses showed that diabetes conferred a $44 \%$ greater excess risk of incident CHD in women than men [8]. A significant sex difference was also observed in a 
Fig. 2 Multiple-adjusted RR for heart failure, comparing individuals with type 1 and type 2 diabetes with those without diabetes for (a) women and (b) men. APCSC, Asia Pacific Cohort Studies Collaboration; CALIBER, Cardiovascular disease research using LInked Bespoke studies and Electronic health Records; CHS, Cardiovascular Health Study; KPMCP, Northern California Kaiser Permanente Medical Care Program; LRPP, Cardiovascular Disease Lifetime Risk Pooling Project (Framingham Heart, Framingham Offspring, Atherosclerosis Risk In Communities [ARIC], Chicago Heart Association Detection Project in Industry Study [CHA]); NDR, National Diabetes Registry; NHANES I, First National Health and Nutrition Examination Survey; NHI, National Health Insurance; NHS, National Health Service a

\begin{tabular}{l|lll} 
Study & \\
\hline $\begin{array}{l}\text { Type 1 } \\
\text { NHS Information Services Scotland [18] }\end{array}$ & & \\
Swedish NDR [27] \\
Subtotal $\left(I^{2}=78.4 \%, p=0.031\right)$
\end{tabular}

b

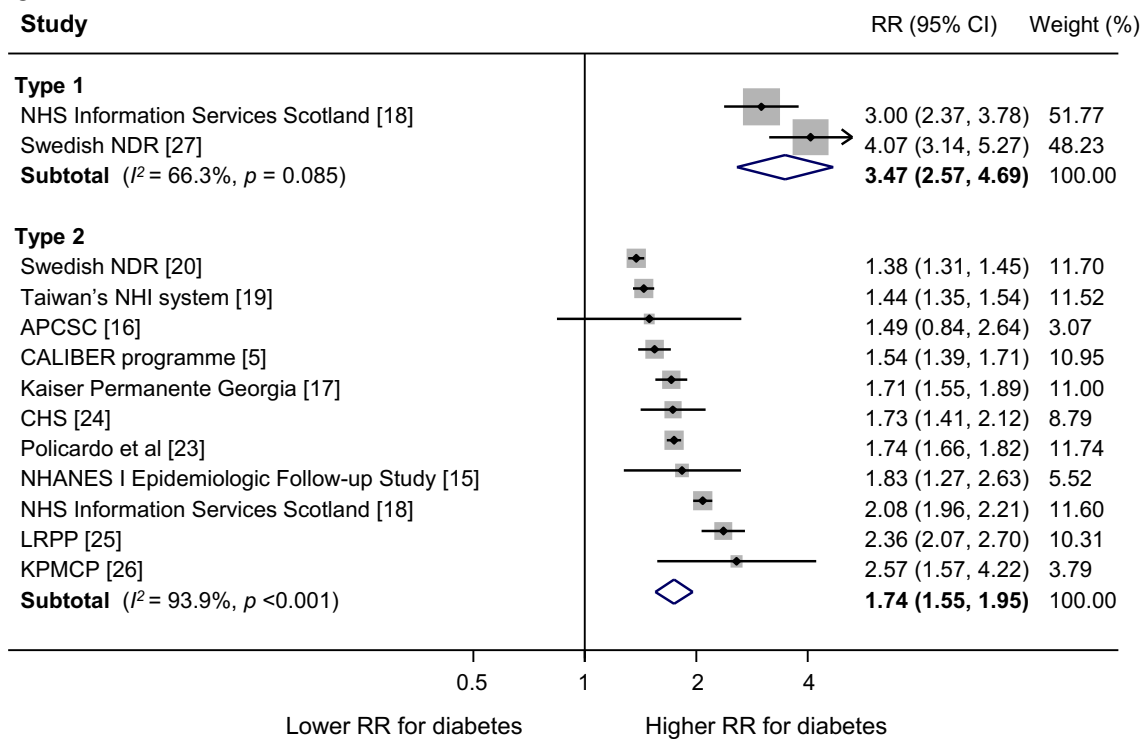

meta-analysis which focused specifically on type 1 diabetes and CHD [28]. Sex differences in the management of diabetes could underpin these associations. Historically, women with diabetes had poorer glycaemic control than men with diabetes [30-34]. Second, in addition to CHD, undertreatment for women with diabetes could also contribute to the development of diabetic cardiomyopathy, a form of cardiac dysfunction that occurs independently of CHD and hypertension [35, 36], and could subsequently lead to a stronger association of diabetes with heart failure in women than men. Third, prolonged exposure to hyperglycaemia during the prediabetic state may also be involved. Women were reported to have 2 years longer duration of prediabetes than men [37]. Longer duration of prediabetes has been shown to be associated with left ventricular systolic and diastolic dysfunction [38]. Finally, it is also possible that sex differences in other cardiovascular risk factor profiles [30-33, 39-41] account for the greater excess risk of heart failure associated with diabetes in women compared with men. Deteriorations in major cardiovascular risk factor levels in individuals with diabetes compared with those without diabetes are reported to be greater in women than in men [9, 42, 43].

It might be also possible that the sex differences found in this study are a mathematical artefact caused by the relatively low absolute risk for heart failure in women compared with men. Suppose that the absolute risk difference following diabetes is the same in men as it is in women, then there would automatically be a larger RR among women compared with 


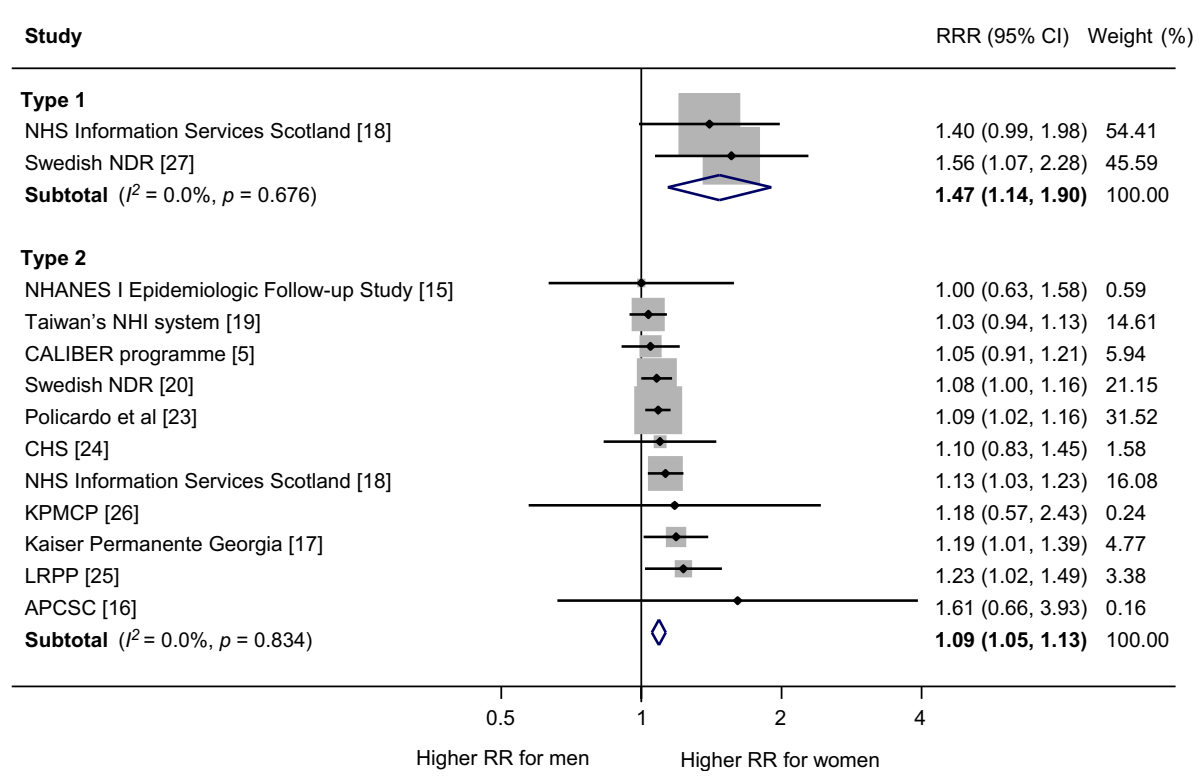

Fig. 3 Multiple-adjusted women-to-men RRR for heart failure, comparing individuals with type 1 and type 2 diabetes with those without diabetes. APCSC, Asia Pacific Cohort Studies Collaboration; CALIBER, Cardiovascular disease research using LInked Bespoke studies and Electronic health Records; CHS, Cardiovascular Health Study; KPMCP, Northern California Kaiser Permanente Medical Care Program; LRPP,

men. However, RRs, rather than absolute risk differences, are much more commonly reported in clinical studies, given their stability across different populations. No sex differences between women and men were found in our previous metaanalyses for risk factors and cardiovascular diseases [44,
Cardiovascular Disease Lifetime Risk Pooling Project (Framingham Heart, Framingham Offspring, Atherosclerosis Risk In Communities [ARIC], Chicago Heart Association Detection Project in Industry Study [CHA]); NDR, National Diabetes Registry; NHANES I, First National Health and Nutrition Examination Survey; NHI, National Health Insurance; NHS, National Health Service

45], which indicates that detection of a female disadvantage based on RRs is not inevitable.

Regarding type of diabetes, the excess risk of heart failure associated with diabetes was greater in type 1 diabetes than type 2 diabetes. The women-to-men RRR was 1.47 (95\% CI
Fig. 4 Subgroup analyses of multiple-adjusted women-to-men RRR for heart failure, comparing individuals with type 2 diabetes with those without. ${ }^{\mathrm{a}}$ Year of baseline: two studies were excluded because baseline year bridged pre-1985 and 1986 onwards. ${ }^{\mathrm{b}}$ Absolute risk of heart failure: absolute risk was derived using data from individuals with and without diabetes combined. Four studies were excluded because absolute risk was not available for both sexes

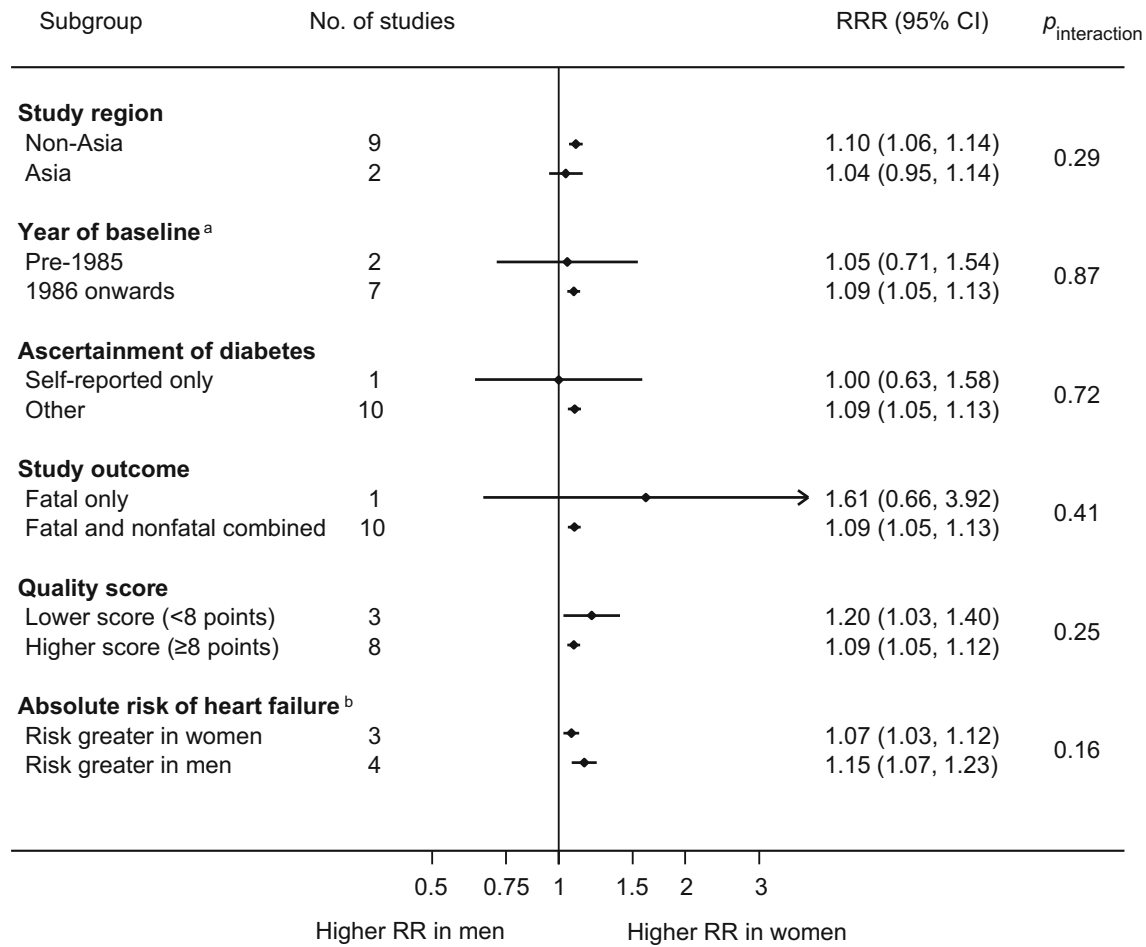


$1.14,1.90)$ for type 1 diabetes, and $1.09(1.05,1.13)$ for type 2 diabetes. The reason for this difference between type 1 and type 2 diabetes is unclear, but it may be partly explained by the above-mentioned sex differences in the association between diabetes and CHD. In our previous meta-analyses, type 1 diabetes showed a stronger sex difference in the association with incident CHD than type 2 diabetes, with women-to-men RRR of 2.54 $(1.80,3.60)$ for type 1 diabetes [28] and 1.44 (1.27, 1.63) for type 2 diabetes [8]. Future large-scale individual participant data meta-analysis and mechanistic studies might elucidate this difference.

The strengths of this meta-analysis are the large number of study participants and exclusion of studies which provided data for only one sex, which reduced the risk of both sampling and non-sampling error. This enabled us to provide robust evidence on the presence of sex differences in the risk of heart failure conferred by diabetes. Furthermore, the findings were consistent across a range of prespecified subgroups. Some limitations of this study should be mentioned. First, this meta-analysis was based on published data, with heterogeneity in study design, ascertainment of diabetes, definition of endpoint and extent of adjustment for confounding factors across studies. However, since we only included studies with results for both sexes, we minimised these issues by conducting within-study comparisons of the sexes. Second, there may be other unmeasured confounding factors in addition to those adjusted for in each study. Third, information on duration of diabetes, glycaemic control, glucose-lowering drugs or phenotype of heart failure was not available, and thus we cannot conduct detailed assessments regarding these factors. Analyses considering these factors would provide insight into potential explanation for the observed sex differences, and will be the subject of our future research. Fourth, the competing risk of premature death was not adjusted for in the present metaanalysis. Men with diabetes are at an increased risk of premature death compared with women with diabetes [46] (as indeed is the case in general populations), and therefore may be less likely to develop heart failure. This could partly explain the greater excess risk of heart failure following diagnosis of diabetes in women than men. Finally, we only found two studies of type 1 diabetes, which compromises the accuracy of our estimates in this regard. Additional studies are needed to address this issue.

In conclusion, the excess risk of heart failure following diagnosis of diabetes is significantly greater in women than men, highlighting the importance of intensive prevention and treatment of diabetes for women as well as men. Further research is required to understand the mechanisms underpinning the excess risk of heart failure conferred by diabetes (particularly type 1) in women and to reduce the burden associated with diabetes in both sexes.
Data availability The datasets generated during and/or analysed during the current study are available from the corresponding author on reasonable request.

Funding This study received no external funding. TO is supported by the John Chalmers Clinical Research Fellowship of the George Institute. SAEP is supported by a Medical Research Council (UK) fellowship and MW is supported by a National Health and Medical Research Council (Australia) fellowship and Program Grant.

Duality of interest MW is a consultant to Amgen and Kirin. All other authors declare that there is no duality of interest associated with their contribution to this manuscript.

Contribution statement TO conceived the research, conducted the systematic review and all the analyses, and wrote the paper. YK conducted the systematic review and made critical revision of the manuscript. MW supervised the work and, together with SAEP, interpreted the data and made critical revision of the manuscript. All authors gave final approval of the version to be published. TO is the guarantor of this work.

Open Access This article is distributed under the terms of the Creative Commons Attribution 4.0 International License (http:// creativecommons.org/licenses/by/4.0/), which permits unrestricted use, distribution, and reproduction in any medium, provided you give appropriate credit to the original author(s) and the source, provide a link to the Creative Commons license, and indicate if changes were made.

\section{References}

1. Seferovic PM, Petrie MC, Filippatos GS et al (2018) Type 2 diabetes mellitus and heart failure: a position statement from the Heart Failure Association of the European Society of Cardiology. Eur J Heart Fail 20(5):853-872. https://doi.org/10.1002/ejhf.1170

2. Aune D, Schlesinger S, Neuenschwander M et al (2018) Diabetes mellitus, blood glucose and the risk of heart failure: a systematic review and meta-analysis of prospective studies. Nutr Metab Cardiovasc Dis 28(11):1081-1091. https://doi.org/10.1016/j. numecd.2018.07.005

3. Dauriz M, Targher G, Laroche C et al (2017) Association between diabetes and 1-year adverse clinical outcomes in a multinational cohort of ambulatory patients with chronic heart failure: results from the ESC-HFA heart failure long-term registry. Diabetes Care 40(5):671-678. https://doi.org/10.2337/dc16-2016

4. Johansson I, Edner M, Dahlstrom U, Nasman P, Ryden L, Norhammar A (2014) Is the prognosis in patients with diabetes and heart failure a matter of unsatisfactory management? An observational study from the Swedish Heart Failure Registry. Eur J Heart Fail 16(4):409-418. https://doi.org/10.1002/ejhf.44

5. Shah AD, Langenberg C, Rapsomaniki E et al (2015) Type 2 diabetes and incidence of cardiovascular diseases: a cohort study in 1.9 million people. Lancet Diabetes Endocrinol 3(2):105-113. https:// doi.org/10.1016/S2213-8587(14)70219-0

6. Sattar N, Preiss D (2018) Research digest: heart failure in diabetes comes into focus. Lancet Diabetes Endocrinol 6(8):603. https://doi. org/10.1016/S2213-8587(18)30212-2

7. Regensteiner JG, Golden S, Huebschmann AG et al (2015) Sex differences in the cardiovascular consequences of diabetes mellitus: a scientific statement from the American Heart Association. Circulation 132(25):2424-2447. https://doi.org/10.1161/CIR. 0000000000000343 
8. Peters SA, Huxley RR, Woodward M (2014) Diabetes as risk factor for incident coronary heart disease in women compared with men: a systematic review and meta-analysis of 64 cohorts including 858 , 507 individuals and 28,203 coronary events. Diabetologia 57(8): 1542-1551. https://doi.org/10.1007/s00125-014-3260-6

9. Peters SA, Huxley RR, Woodward M (2014) Diabetes as a risk factor for stroke in women compared with men: a systematic review and meta-analysis of 64 cohorts, including 775,385 individuals and 12,539 strokes. Lancet 383(9933):1973-1980. https://doi.org/10. 1016/S0140-6736(14)60040-4

10. Chatterjee S, Peters SA, Woodward M et al (2016) Type 2 diabetes as a risk factor for dementia in women compared with men: a pooled analysis of 2.3 million people comprising more than 100 , 000 cases of dementia. Diabetes Care 39(2):300-307. https://doi. org $/ 10.2337 / \mathrm{dc} 15-1588$

11. Ohkuma T, Peters SAE, Woodward M (2018) Sex differences in the association between diabetes and cancer: a systematic review and meta-analysis of 121 cohorts including 20 million individuals and one million events. Diabetologia 61(10):2140-2154. https://doi. org/10.1007/s00125-018-4664-5

12. Stroup DF, Berlin JA, Morton SC et al (2000) Meta-analysis of observational studies in epidemiology: a proposal for reporting. Meta-analysis Of Observational Studies in Epidemiology (MOOSE) group. JAMA 283(15):2008-2012. https://doi.org/10. 1001/jama.283.15.2008

13. American Diabetes Association (2019) Standards of medical care in diabetes-2019. Diabetes Care 42:S1-S186

14. Wells G, Shea B, O'Connell D et al. The Newcastle-Ottawa Scale (NOS) for assessing the quality of nonrandomised studies in metaanalyses. www.ohri.ca/programs/clinical_epidemiology/oxford. asp. Accessed 19 Dec 2018

15. He J, Ogden LG, Bazzano LA, Vupputuri S, Loria C, Whelton PK (2001) Risk factors for congestive heart failure in US men and women: NHANES I epidemiologic follow-up study. Arch Intern Med 161(7):996-1002. https://doi.org/10.1001/archinte.161.7.996

16. Huxley RR, Barzi F, Woo J et al (2014) A comparison of risk factors for mortality from heart failure in Asian and non-Asian populations: an overview of individual participant data from 32 prospective cohorts from the Asia-Pacific Region. BMC Cardiovasc Disord 14(1): 61. https://doi.org/10.1186/1471-2261-14-61

17. Goyal A, Norton CR, Thomas TN et al (2010) Predictors of incident heart failure in a large insured population: a one million person-year follow-up study. Circ Heart Fail 3(6):698-705. https://doi.org/10. 1161/CIRCHEARTFAILURE.110.938175

18. McAllister DA, Read S, Kerssens J et al (2018) Incidence of hospitalisation for heart failure and case-fatality among 3.25 million people with and without diabetes. Circulation 138(24):2774-2786. https://doi.org/10.1161/CIRCULATIONAHA.118.034986

19. Chen HF, Ho CA, Li CY (2019) Risk of heart failure in a population with type 2 diabetes versus a population without diabetes with and without coronary heart disease. Diabetes Obes Metab 21(1):112119. https://doi.org/10.1111/dom.13493

20. Rosengren A, Edqvist J, Rawshani A et al (2018) Excess risk of hospitalisation for heart failure among people with type 2 diabetes. Diabetologia 61(11):2300-2309. https://doi.org/10.1007/s00125018-4700-5

21. Ballotari P, Venturelli F, Greci M, Giorgi Rossi P, Manicardi V (2017) Sex differences in the effect of type 2 diabetes on major cardiovascular diseases: results from a population-based study in Italy. Int J Endocrinol 2017:6039356

22. Leung AA, Eurich DT, Lamb DA et al (2009) Risk of heart failure in patients with recent-onset type 2 diabetes: population-based cohort study. J Card Fail 15(2):152-157. https://doi.org/10.1016/j. cardfail.2008.10.004

23. Policardo L, Seghieri G, Francesconi P, Anichini R, Franconi F, Del Prato S (2017) Gender difference in diabetes related excess risk of cardiovascular events: when does the 'risk window' open? J Diabetes Complicat 31(1):74-79. https://doi.org/10.1016/j. jdiacomp.2016.09.010

24. Vimalananda VG, Biggs ML, Rosenzweig JL et al (2014) The influence of sex on cardiovascular outcomes associated with diabetes among older black and white adults. J Diabetes Complicat 28(3):316-322. https://doi.org/10.1016/j.jdiacomp.2013.12.004

25. Ahmad FS, Ning H, Rich JD, Yancy CW, Lloyd-Jones DM, Wilkins JT (2016) Hypertension, obesity, diabetes, and heart failure-free survival: the cardiovascular disease Lifetime Risk Pooling Project. JACC Heart Fail 4(12):911-919. https://doi.org/ 10.1016/j.jchf.2016.08.001

26. Alexander M, Grumbach K, Selby J, Brown AF, Washington E (1995) Hospitalization for congestive heart failure. Explaining racial differences. JAMA 274(13):1037-1042. https://doi.org/10. 1001/jama.1995.03530130043026

27. Rosengren A, Vestberg D, Svensson AM et al (2015) Long-term excess risk of heart failure in people with type 1 diabetes: a prospective case-control study. Lancet Diabetes Endocrinol 3(11):876885. https://doi.org/10.1016/S2213-8587(15)00292-2

28. Huxley RR, Peters SA, Mishra GD, Woodward M (2015) Risk of all-cause mortality and vascular events in women versus men with type 1 diabetes: a systematic review and meta-analysis. Lancet Diabetes Endocrinol 3(3):198-206. https://doi.org/10.1016/ S2213-8587(14)70248-7

29. Shen Y, Cai R, Sun J et al (2017) Diabetes mellitus as a risk factor for incident chronic kidney disease and end-stage renal disease in women compared with men: a systematic review and meta-analysis. Endocrine 55(1):66-76. https://doi.org/10.1007/s12020-016-1014-6

30. Penno G, Solini A, Bonora E et al (2013) Gender differences in cardiovascular disease risk factors, treatments and complications in patients with type 2 diabetes: the RIACE Italian multicentre study. J Intern Med 274(2):176-191. https://doi.org/10.1111/joim.12073

31. Wexler DJ, Grant RW, Meigs JB, Nathan DM, Cagliero E (2005) Sex disparities in treatment of cardiac risk factors in patients with type 2 diabetes. Diabetes Care 28(3):514-520. https://doi.org/10. 2337/diacare.28.3.514

32. Vaccaro O, Boemi M, Cavalot $\mathrm{F}$ et al (2008) The clinical reality of guidelines for primary prevention of cardiovascular disease in type 2 diabetes in Italy. Atherosclerosis 198(2):396-402. https://doi.org/ 10.1016/j.atherosclerosis.2007.10.026

33. Nilsson PM, Theobald H, Journath G, Fritz T (2004) Gender differences in risk factor control and treatment profile in diabetes: a study in 229 Swedish primary health care centres. Scand J Prim Health Care 22(1):27-31. https://doi.org/10.1080/02813430310003264

34. Petitti DB, Klingensmith GJ, Bell RA et al (2009) Glycemic control in youth with diabetes: the SEARCH for Diabetes in Youth Study. J Pediatr 155(5):668-672.e1-3. https://doi.org/10.1016/j.jpeds.2009. 05.025

35. Boudina S, Abel ED (2007) Diabetic cardiomyopathy revisited. Circulation 115(25):3213-3223. https://doi.org/10.1161/ CIRCULATIONAHA.106.679597

36. Ryden L, Grant PJ, Anker SD et al (2013) ESC guidelines on diabetes, pre-diabetes, and cardiovascular diseases developed in collaboration with the EASD: the task force on diabetes, pre-diabetes, and cardiovascular diseases of the European Society of Cardiology (ESC) and developed in collaboration with the European Association for the Study of Diabetes (EASD). Eur Heart J 34(39):3035-3087. https://doi.org/10.1093/eurheartj/ eht108

37. Bertram MY, Vos T (2010) Quantifying the duration of pre-diabetes. Aust N Z J Public Health 34(3):311-314. https://doi.org/10. 1111/j.1753-6405.2010.00532.x

38. Reis JP, Allen NB, Bancks MP et al (2018) Duration of diabetes and prediabetes during adulthood and subclinical atherosclerosis and 
cardiac dysfunction in middle age: the CARDIA study. Diabetes Care 41(4):731-738. https://doi.org/10.2337/dc17-2233

39. Gouni-Berthold I, Berthold HK, Mantzoros CS, Bohm M, Krone W (2008) Sex disparities in the treatment and control of cardiovascular risk factors in type 2 diabetes. Diabetes Care 31(7):1389-1391. https://doi.org/10.2337/dc08-0194

40. Gobl CS, Brannath W, Bozkurt L et al (2010) Sex-specific differences in glycemic control and cardiovascular risk factors in older patients with insulin-treated type 2 diabetes mellitus. Gend Med 7(6):593-599. https://doi.org/10.1016/j.genm.2010.11.003

41. Duggirala MK, Cuddihy RM, Cuddihy MT, Nyman MA, Naessens JM, Pankratz VS (2005) Women with diabetes have poorer control of blood pressure than men. J Women's Health 14(5):418-423. https://doi.org/10.1089/jwh.2005.14.418

42. Wannamethee SG, Papacosta O, Lawlor DA et al (2012) Do women exhibit greater differences in established and novel risk factors between diabetes and non-diabetes than men? The British Regional Heart Study and British Women's Heart Health Study. Diabetologia 55(1):80-87. https://doi.org/10.1007/s00125-011-2284-4

43. Howard BV, Cowan LD, Go O, Welty TK, Robbins DC, Lee ET (1998) Adverse effects of diabetes on multiple cardiovascular disease risk factors in women. The Strong Heart Study. Diabetes Care 21(8):1258-1265. https://doi.org/10.2337/diacare.21.8.1258

44. Peters SA, Huxley RR, Woodward M (2013) Comparison of the sex-specific associations between systolic blood pressure and the risk of cardiovascular disease: a systematic review and metaanalysis of 124 cohort studies, including 1.2 million individuals. Stroke 44(9):2394-2401. https://doi.org/10.1161/STROKEAHA. 113.001624

45. Mongraw-Chaffin ML, Peters SA, Huxley RR, Woodward M (2015) The sex-specific association between BMI and coronary heart disease: a systematic review and meta-analysis of 95 cohorts with 1.2 million participants. Lancet Diabetes Endocrinol 3(6): 437-449. https://doi.org/10.1016/S2213-8587(15)00086-8

46. Baena-Diez JM, Penafiel J, Subirana I et al (2016) Risk of causespecific death in individuals with diabetes: a competing risks analysis. Diabetes Care 39(11):1987-1995. https://doi.org/10.2337/ dc16-0614

Publisher's note Springer Nature remains neutral with regard to jurisdictional claims in published maps and institutional affiliations. 